\title{
An obesogenic island in the Mediterranean: mapping potential drivers of obesity in Malta
}

\author{
Daniel Cauchi*, Harry Rutter and Cecile Knai \\ Department of Health Services Research and Policy, London School of Hygiene and Tropical Medicine, \\ 15-17 Tavistock Place, Room LG13, London WC1H 9SH, UK
}

Submitted 11 September 2014: Final revision received 16 December 2014: Accepted 29 January 2014

\begin{abstract}
Objective: The prevalence of childhood and adult obesity in Malta is among the highest in the world. Although increasingly recognised as a public health problem with substantial future economic implications for the national health and social care systems, understanding the context underlying the burden of obesity is necessary for the development of appropriate counter-strategies.

Design: We conducted a contextual analysis to explore factors that may have potentially contributed to the establishment of an obesogenic environment in Malta. A search of the literature published between 1990 and 2013 was conducted in MEDLINE and EMBASE. Twenty-two full-text articles were retrieved. Additional publications were identified following recommendations by Maltese public health experts; a review of relevant websites; and thorough hand searching of back issues of the Malta Medical Journal since 1990.

Setting: Malta.

Subjects: Whole population, with a focus on children.

Results: Results are organised and presented using the ANalysis Grid for Elements Linked to Obesity (ANGELO) framework. Physical, economic, policy and sociocultural dimensions of the Maltese obesogenic environment are explored.

Conclusions: Malta's obesity rates may be the result of an obesogenic environment characterised by limited infrastructure for active living combined with an energy-dense food supply. Further research is required to identify and quantify the strength of interactions between these potential environmental drivers of obesity in order to enable appropriate countermeasures to be developed.
\end{abstract}

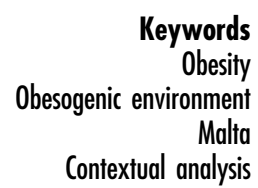

The rapid rise in overweight and obesity rates over recent decades is increasingly recognised as a complex and costly public health problem of global magnitude ${ }^{(1-3)}$. The prevalence of childhood and adult obesity in Malta is among the highest worldwide ${ }^{(4-6)}$. Obesity is a precursor of non-communicable diseases including IHD, cerebrovascular disease and several types of cancer that collectively account for the majority of deaths in Malta ${ }^{(7)}$. In 2010 over $40 \%$ of a national cohort of 10 -year-old children were classified as either overweight or obese according to criteria of the International Obesity Task Force (now known as the World Obesity Federation $\dagger$ ), a substantial increase from the $26 \%$ prevalence measured three years

$\uparrow$ World Obesity Federation (formerly the International Obesity Task Force) is a global network of experts working to alert the world to the growing health crisis caused by soaring levels of obesity (http://www. worldobesity.org/what-we-do/policy-prevention/). previously ${ }^{(8,9)}$. Other studies using different methods have reported similar findings in younger as well as older Maltese children ${ }^{(10-12)}$. The economic implications for the national health and social care systems are significant, with estimated annual direct costs attributable to the consequences of overweight and obesity in the population aged 15 years and over of about $€ 20$ million in 2008. This included medical expenses such as in-patient stays, daypatient stays and consultations with general practitioners and specialists, but excluded costs related to medication, no change in the proportion of overweight and obese individuals in the population, the projected cost for 2020 would increase by about $€ 6$ million. However, the authors cautioned that increasing overweight and obesity rates in recent years suggest these calculations are likely to grossly underestimate the true cost ${ }^{(13)}$. surgery, ancillary services and loss of income. Assuming 
In light of this situation, the Maltese government has launched a number of strategy and policy documents outlining targets and measures intended to increase physical activity and improve nutrition across the population ${ }^{(14-18)}$. These include a national obesity strategy that outlines a range of possible economic and fiscal measures, targeted multidisciplinary programmes and changes to the environment ${ }^{(14)}$; ongoing education reforms aiming to modify the school nutrition environment and positively affect time allocated to physical activity during or after school hours ${ }^{(16,19,20)}$; and policies to improve the local physical environment taking into account environmental, economic, social, cultural and infrastructural considerations ${ }^{(18)}$. However, while political commitments to address obesity in Malta seem to heed the call for a shift in emphasis from treatment of already obese children to prevention and policy-level changes, actions promoting major changes to the physical, economic and social environment have not been implemented, with the majority of current measures predominantly focusing on improving consumer knowledge.

The 'obesogenic' environment is defined as 'the sum of influences that the surroundings, opportunities, or conditions of life have on promoting obesity in individuals or populations'. Tackling this obesogenicity requires system-wide environmental interventions that complement educational and behavioural measures in order to create supportive environments ${ }^{(21)}$. Population-level environmental interventions are cost-effective measures to achieve lasting reductions in obesity because they become incorporated into structures, systems, policies and sociocultural norms ${ }^{(21-23)}$. However, it is likely that strategies to combat obesity will be more effective if they are appropriate to the national context ${ }^{(24,25)}$. A recently published framework for monitoring and benchmarking of food environments recommends that an initial country-level contextual analysis be carried out ${ }^{(26)}$ to outline country characteristics and factors influencing food composition or nutrient profiles ${ }^{(27)}$, food prices ${ }^{(28)}$, as well as the status of existing government and private-sector policies and actions related to food environments, obesity and noncommunicable disease ${ }^{(29)}$. The present paper maps out potential drivers of obesity in Malta and outlines areas where further research would be beneficial.

\section{Methods}

We conducted a contextual analysis to explore factors contributing to the establishment of an obesogenic environment in Malta, informed by a review of the literature around obesity, physical activity and nutrition in Malta published between 1990 and 2013. Two electronic databases (MEDLINE and EMBASE) were searched using the following key search terms: 'Malta', 'obesity', 'nutrition', 'food' and 'physical activity'; 109 articles were identified. After reviewing abstracts, eighty-seven papers were rejected and twenty-two full-text articles were retrieved. Additional publications were identified following recommendations by Maltese public health experts; a review of relevant Maltese websites; and thorough hand searching of back issues of the Malta Medical Journal since 1990 .

Results are organised and presented using the ANalysis Grid for Elements Linked to Obesity (ANGELO) framework $^{(21)}$. This diagnostic tool, which has been used to conceptualise the obesogenic environment and prioritise action points for obesity prevention in communities ${ }^{(30)}$, outlines two levels of environment: (i) the microenvironment within which individuals typically interact on a daily basis (such as the home, school, workplace, neighbourhood); and (ii) the broader macro-environments which tend to be outside direct individual control. These include large, geographically diffuse sectors such as the education and health systems, government and private sectors, and the food industry. Each environmental level in turn comprises four possible dimensions that potentially affect population-level nutrition and physical activity: (i) the physical dimension describes factors such as urban design, transportation and the home or neighbourhood built environment; (ii) the economic dimension encompasses factors such as income, education and socioeconomic status at the micro level; (iii) the policy dimension describes national or regional policies and regulations at the macro level; and (iv) socio-cultural factors refer to the broader context within which individuals live, such as societal norms about nutrition and family behaviour. These four dimensions interact to influence people's diet and physical activity choices, and are explored in a narrative fashion to illustrate why Malta could be described as an 'obesogenic' island in the Mediterranean.

\section{Results}

Factors affecting nutrition and physical activity are presented separately below for the macro- and micro-environments.

\section{The macro-environment}

\section{Factors affecting nutrition}

Historical context and the nutrition transition in Malta Malta's small size, colonial heritage, its longstanding cultural and commercial links with and proximity to mainland Europe, and its longstanding dependence on imported foodstuffs have fundamentally conditioned the food system and dietary norms of the Maltese ${ }^{(31)}$. Tourism, media and the effect of globalisation in the decades since the 1960s have also had an impact on the consumption of convenience and luxury foods ${ }^{(32)}$. Thus, despite its central Mediterranean location, the diet prevalent in Malta cannot be said to be truly 'Mediterranean'(33-35), instead 
Obesity in Malta: a contextual analysis

Table 1 Major sources of dietary energy $(\mathrm{kcal})^{\star}$, 1961-2010, Malta (from FAOSTAT ${ }^{(55)}$ )

\begin{tabular}{|c|c|c|c|c|c|c|c|c|c|c|c|}
\hline & 1961 & 1965 & 1970 & 1975 & 1980 & 1985 & 1990 & 1995 & 2000 & 2005 & 2010 \\
\hline Cereals & 1259 & 1270 & 1213 & 1228 & 1170 & 1054 & 1001 & 1035 & 1079 & 1114 & 1086 \\
\hline Starchy roots & 85 & 71 & 27 & 55 & 54 & 58 & 55 & 104 & 132 & 114 & 99 \\
\hline Sugar and sweeteners & 367 & 421 & 510 & 506 & 527 & 498 & 499 & 487 & 505 & 514 & 529 \\
\hline Pulses & 116 & 121 & 121 & 80 & 35 & 41 & 47 & 51 & 53 & 50 & 47 \\
\hline Tree nuts & 8 & 10 & 8 & 7 & 9 & 12 & 17 & 21 & 24 & 30 & 28 \\
\hline Oilcrops & 17 & 20 & 19 & 18 & 22 & 22 & 29 & 36 & 36 & 40 & 41 \\
\hline Vegetable oils & 199 & 236 & 257 & 218 & 266 & 301 & 316 & 258 & 194 & 166 & 213 \\
\hline Vegetables & 50 & 55 & 67 & 77 & 83 & 83 & 86 & 86 & 122 & 131 & 141 \\
\hline Fruits & 63 & 61 & 68 & 75 & 75 & 80 & 93 & 127 & 117 & 118 & 105 \\
\hline Alcoholic beverages & 25 & 28 & 46 & 61 & 89 & 78 & 89 & 99 & 98 & 93 & 103 \\
\hline Meat & 136 & 131 & 160 & 184 & 224 & 225 & 236 & 266 & 277 & 298 & 327 \\
\hline Animal fats & 172 & 161 & 195 & 194 & 231 & 217 & 182 & 177 & 198 & 194 & 161 \\
\hline Eggs & 31 & 38 & 48 & 63 & 70 & 63 & 63 & 66 & 58 & 47 & 53 \\
\hline Milk & 255 & 246 & 258 & 289 & 325 & 298 & 287 & 270 & 316 & 300 & 286 \\
\hline Fish, seafood & 23 & 21 & 21 & 26 & 36 & 30 & 33 & 39 & 55 & 61 & 65 \\
\hline Miscellaneous & 8 & 11 & 16 & 9 & 15 & 17 & 10 & 5 & 9 & 9 & 11 \\
\hline Total & 2846 & 2935 & 3077 & 3138 & 3258 & 3098 & 3074 & 3187 & 3348 & 3366 & 3368 \\
\hline
\end{tabular}

To convert kcal to kJ, multiply kcal by 4.184

*Five-year moving average.

exhibiting '...diet and health patterns more typical of Northern Europe than of the Mediterranean,(36).

\section{Colonial impact}

An 1839 British colonial government report described the diet of the Maltese as consisting mainly of bread, seasonal vegetables and occasional fish, with minimal animal produce $^{(37)}$. This is very similar to the traditional Mediterranean diet that has been shown to significantly reduce incidence of $\mathrm{CVD}^{(38)}$ and which is typically high in olive oil, nut, vegetable, pulses, cereal and fruit intakes with moderate amounts of fish but low meat or dairy product intake ${ }^{(39-44)}$. Since then, the Maltese economy has progressed from one harnessed to the needs of the British colonial administration to a diversified open-market economy that is mainly export-driven, with an emphasis on manufacturing, financial services and tourism. Following a process of trade liberalisation initiated in $1989^{(32)}$ which facilitated the fastfood industry's penetration into the local market, Malta joined the EU in 2004 and is classified as a high-income country by the World Bank.

\section{The nutrition transition}

Table 1 shows that between 1961 and 2010, overall energy availability (in kcal) increased by approximately $21 \%$, supporting claims that daily energy intake in Malta increased significantly during the latter half of the 20th century even as consumption of fatty foods exceeded that consumed in Northern European countries ${ }^{(45)}$. It is likely that the historical influences outlined above, systematic changes to global food production and distribution systems, improving economic conditions and a dependence on foreign imports have consolidated the shift away from the traditional Mediterranean $\operatorname{diet}^{(46,47)}$ and led to the adoption of a more 'Westernised' diet high in refined carbohydrates, meat, SFA and salt ${ }^{(34,35,48)}$. Thus, a century-and-a-half later, a 1986 WHO report portrayed the Maltese diet as an unhealthy one rich in fats and sugar and low in fibre, designating the Maltese as a high-risk group for non-communicable disease $^{(49)}$. An increase in the variety of available foods, allyear-round availability of food items that were previously only available during the local growing season and increased accessibility of energy-dense food products ${ }^{(16)}$ in a cultural environment where food occupies a central role have had predictable results. Results from a food consumption study conducted in 2010 indicated that overall vegetable and fruit intake is low, while pasta, bread and meat intakes are substantial ${ }^{(50)}$. Similarly, previous research on Maltese children's diet showed that intake of carbohydrate-based foods such as pasta, pizza and fastfood-style meals is pervasive, as is consumption of breakfast cereals and soft drinks. On the other hand, very few Maltese children consume sufficient fruit and vegetables ${ }^{(51)}$. The Health Behaviour in School-aged Children (HBSC) studies showed that, between 2002 and 2010, self-reported daily fruit and vegetable consumption has generally decreased while daily soft drink consumption has increased among 11-, 13- and 15-year-olds. However, only reductions in fruit consumption among 11-year-old girls and 15-year-old boys were significant at the $95 \%$ confidence level (17\% reduction, $z=2.57, \quad P=0.01$; and $12 \%$ reduction, $z=2.06$, $P=0 \cdot 04$, respectively $)^{(12,52,53)}$.

Household expenditure data might suggest a similar trend for the general population. Figure 1 indicates that domestic (i.e. excluding tourist) expenditure on food relative to total domestic expenditure has decreased by about $25 \%$ since 1995, while Fig. 2 illustrates domestic expenditure on different food categories as a proportion of total expenditure on food and beverages. Expenditure on meat has since risen slowly but steadily since 1995, in contrast to a gradual decline in expenditure on bread and cereals. Spending on confectionery and sugary products has increased consistently in recent years, even as expenditure on vegetables has decreased. 


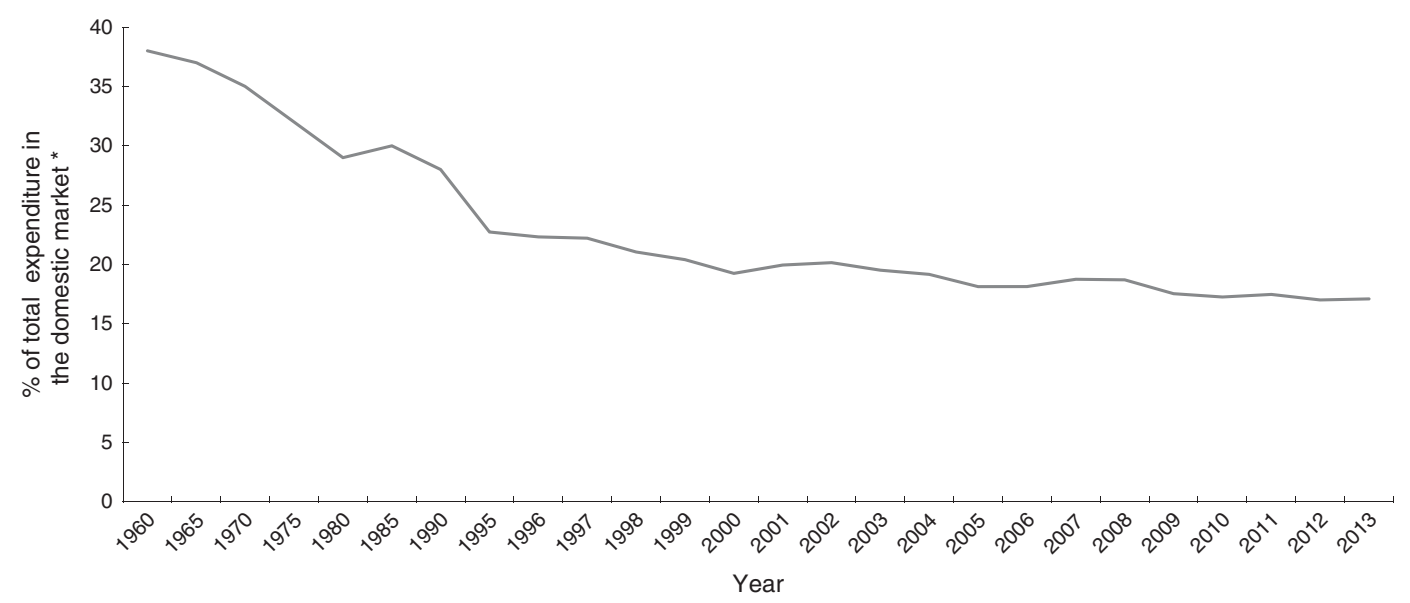

Fig. 1 Expenditure on foods and non-alcoholic beverages as a percentage of total household expenditure*, 1960-2013, Malta (from household expenditure data, Malta (1960-2013) supplied by National Statistics Office, Valletta, personal communication, 2014). ${ }^{*}$ Excludes expenditure by tourists

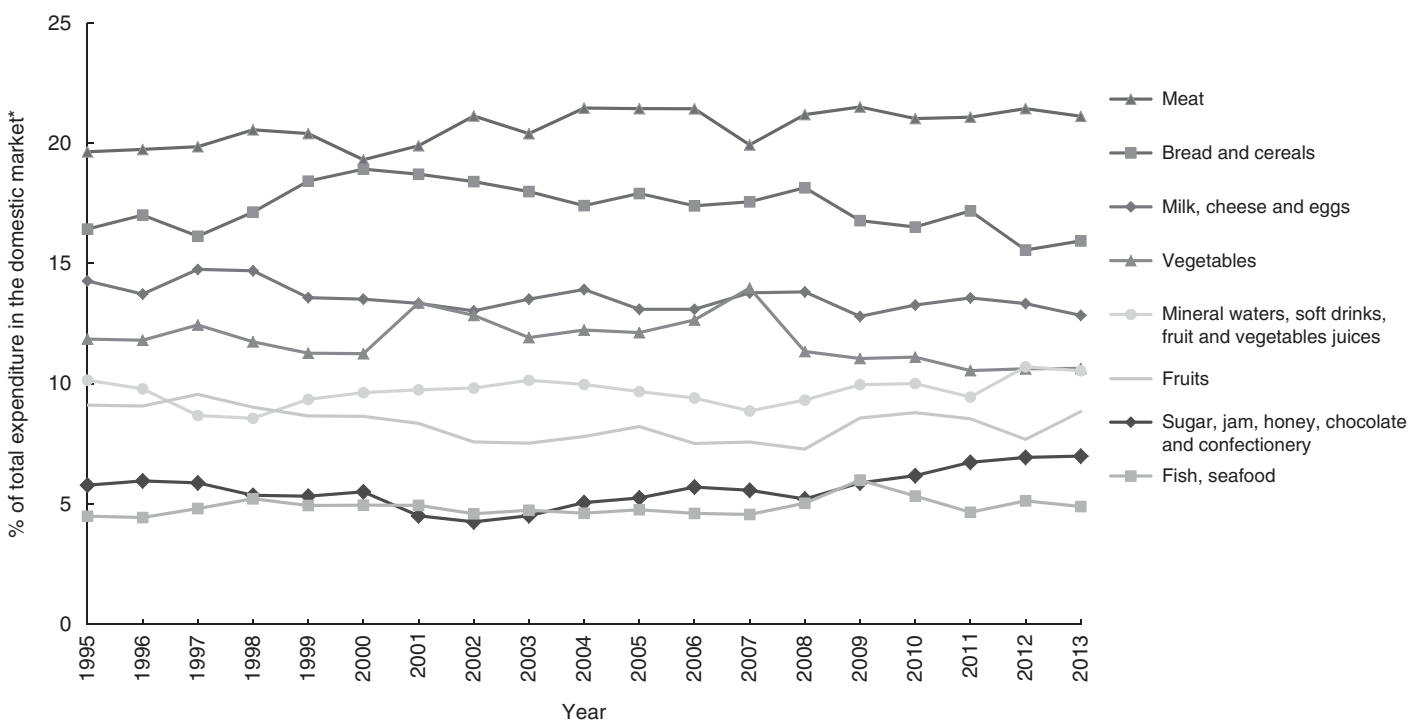

Fig. 2 Expenditure on selected food items as a percentage of total household expenditure on foods and non-alcoholic beverages*, 1995-2013, Malta (from household expenditure data, Malta (1960-2013) supplied by National Statistics Office, Valletta, personal communication, 2014). *Excludes expenditure by tourists

Although food balance sheet* data should be interpreted with caution considering the proportionately large number of tourists visiting Malta compared with the permanent resident population, data in Fig. 3 show a steady increase in the availability of meat and sugar/confectionery. Vegetable, fruit and fish availability have risen slightly, whereas availability of dairy products has remained mostly stable. At the same time, there has been a

* Food balance sheets are compiled annually by the FAO, with countrylevel data on the production and trade of food commodities. A supply/ utilisation account is prepared for each commodity. The food component refers to the total amount of the commodity available for human consumption. The FAO food balance sheets also provide total food availability estimates by aggregating the food component of all commodities These values and population estimates are used to derive and express per person daily dietary energy and protein and fat supplies (http://faostat3. fao.org/faostat-gateway/go/to/mes/glossary/*/E). decline in availability of cereals. Supplies of both protein and fat have increased steadily by $38.8 \%$ and $26.8 \%$, respectively, since the 1960s (Fig. 4(a) and (b)), with a proportionally greater share derived from animal products.

\section{Other socio-cultural aspects}

Malta underwent a sudden shift from food shortage particularly during the Second World War when meat and foods rich in fats and sugar were practically unobtainable - to one of affluence, while at the same time the cultural identity shifted from Mediterranean to Anglo-Saxon ${ }^{(48)}$. Large numbers of Maltese workers who emigrated during the 1950s and 1960s returned decades later with Western food preferences established during their stay in host countries such as Australia, Canada, the USA and the $\mathrm{UK}^{(54)}$. In addition, for many years during and after the Second World 
Obesity in Malta: a contextual analysis

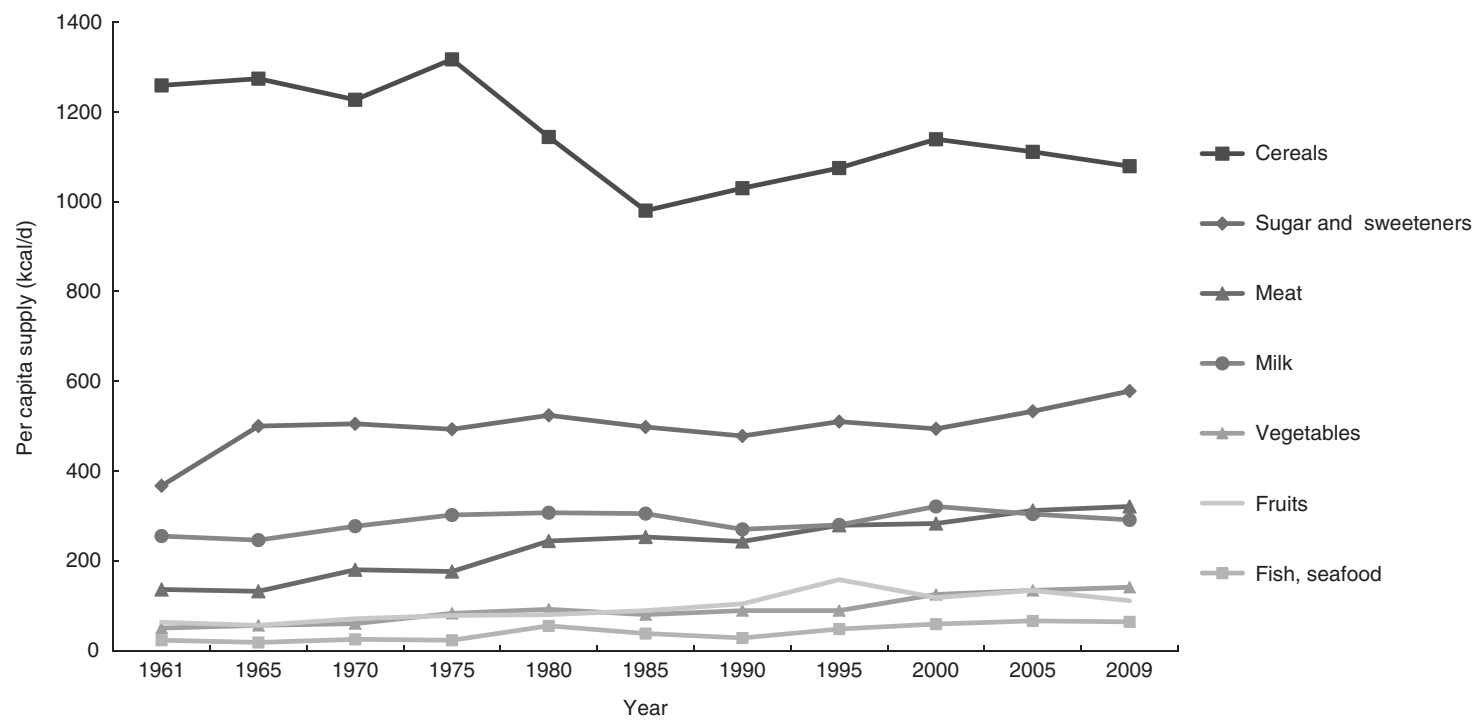

Fig. 3 Per capita supply of selected food categories (kcal/d), 1961-2009, Malta (from FAOSTAT ${ }^{(55)}$ ); to convert kcal to kJ, multiply kcal by 4.184

(a)

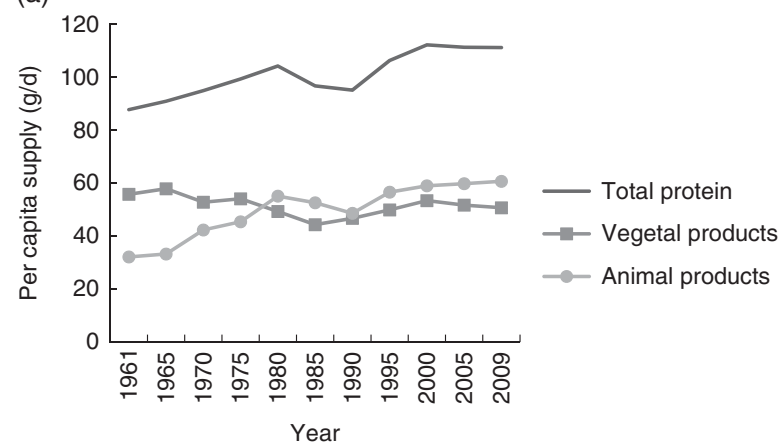

(b)

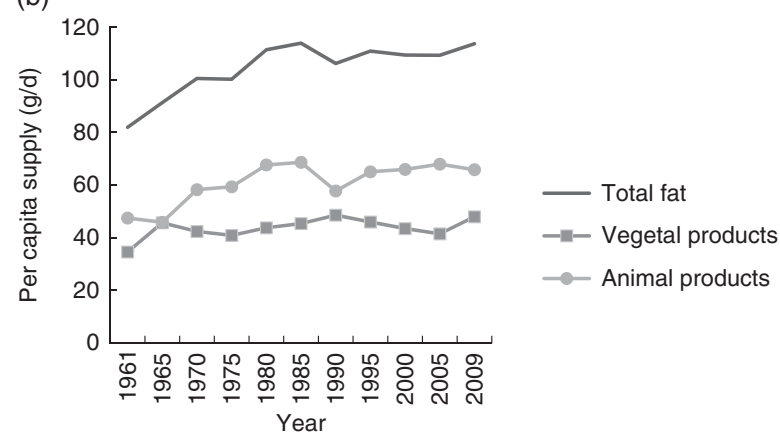

Fig. 4 Per capita supply of (a) protein $(g / d)$ and (b) fat $(g / d)$, 1961-2009, Malta (from FAOSTAT ${ }^{(55)}$ )

War, Malta was greatly dependent on foreign monetary and commodity aid, including imported foods. This may have negatively impacted the type and quality of food available at the time and encouraged the establishment of unhealthy dietary practices. The Maltese consume large amounts of cheddar cheese, sugar, corned beef and condensed milk unusual in the Mediterranean region ${ }^{(32)}$. Although not a producer of sugar, Malta's per capita supply of sugar is the highest in the EU (Fig. 5) and among the highest in the world $^{(55)}$, indicating that sugar could be a major source of energy in the Maltese diet ${ }^{(35)}$.

Thus, in spite of increasing awareness of what constitutes a healthy diet, such a 'socially learned' attitude towards food might have been perpetuated from one generation to the next ${ }^{(56)}$ and remains the norm today. Additionally, the Maltese embrace a number of obesogenic cultural norms, such as a marked preference for large portion sizes ${ }^{(50)}$, a tendency to eat out with family ${ }^{(51,57)}$ and frequent engagement in religious, public or familyoriented feasts and celebrations that are traditionally characterised by an abundance of food. Village 'festas' are distinctive cultural traditions that have been commercialised by the food industry, with a plethora of Maltese and foreign fast foods such as hot dogs, burgers, ice cream, kebabs, chips, nougat, fried pastry and other foods rich in saturated fats and sugars ${ }^{(54)}$.

\section{Food advertising aimed at children}

Television (TV) viewing reduces energy expenditure through displacement of physical activity, is associated with increased energy intake from snacking and entails exposure to food advertising ${ }^{(58)}$. Local research suggests that a majority of primary-school children regularly exert pressure on parents to purchase foods advertised on $\mathrm{TV}^{(57)}$. The introduction of cable TV to the islands in 1991 increased the selection of local and foreign (Italian, British and American) programming and advertising to children ${ }^{(51)}$. Studies have suggested that food marketing targeting children is pervasive in Malta, particularly through pointcollection schemes, sponsorship of school events and children's TV programmes, distribution of free materials in schools, offering 'free' gifts with fast-food meals and TV 


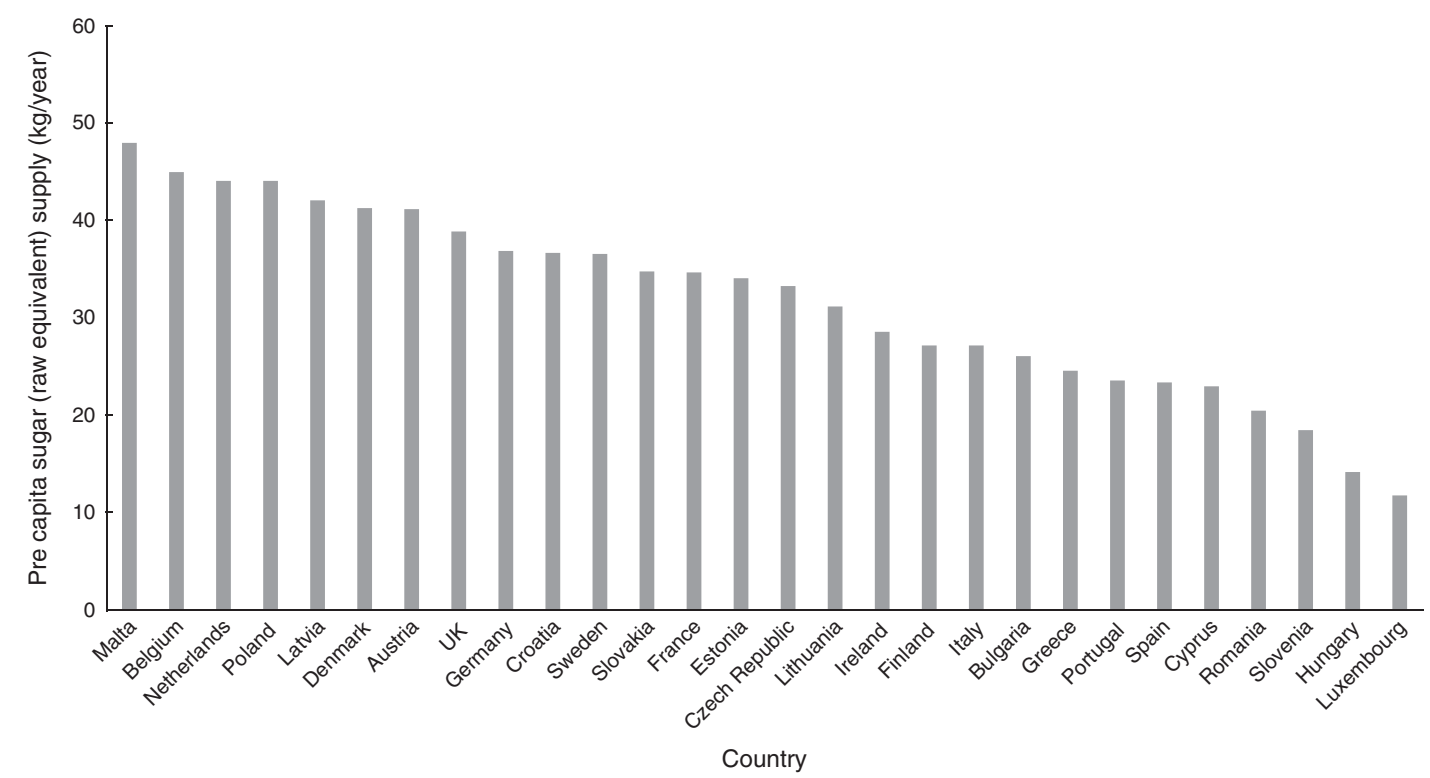

Fig. 5 Per capita supply of sugar (raw equivalent) to EU-28 countries, 2011 (from FAOSTAT ${ }^{(55)}$ )

food advertising ${ }^{(59)}$. A content analysis of food advertising on Maltese TV stations during children's viewing hours revealed systematic promotion of fast foods, breakfast cereals, fruit squash mixers and confectionery items ${ }^{(60)}$.

\section{Factors affecting physical activity}

Topopography and climate

Malta is one of the most densely populated countries in the world ${ }^{(61)}$ and this has been reflected in significantly changing land use over time. Currently, there is a relatively high proportion of urban/industrial land cover (29.7\% of the total land area in 2008, up from $21.5 \%$ in 2000). This represents a rate of development about three times the EU average $^{(7)} ; 51 \%$ of the Maltese islands is devoted to agricultural use and the remaining $18 \%$ is covered by natural vegetation $^{(62)}$. It may be argued that excessive land development has reduced the availability of outdoor spaces where children can be active. Certainly, population participation in sports remains alarmingly low ${ }^{(17)}$ with about $72 \%$ of the adult population characterised as being physically inactive in a recent international study ${ }^{(63)}$. Additionally, Malta's typical Mediterranean climate is characterised by hot, dry summers and mild, rainy winters ${ }^{(61)}$. Temperatures in summer can exceed $35^{\circ} \mathrm{C}$, with high levels of humidity often making the outdoors uncomfortable. High temperatures are associated with reduced physical activity ${ }^{(64)}$, hence climate may also contribute to the low levels of physical activity observed.

\section{Transport preferences}

In spite of a fiscal regime imposing relatively high taxation on car registration and purchase of polluting cars together with high fuel costs, Malta has one of the highest per capita car ownership levels in the EU: 607 cars per 1000 inhabitants in $2009^{(65)}$. Moreover, $19.6 \%$ of households own three cars or more ${ }^{(66)}$. In spite of Malta's small size and lack of significant inter-city distances that in other countries account for a large proportion of kilometres travelled per passenger, data indicate that three-quarters (74.6\%) of all journeys are undertaken using private passenger cars ${ }^{(66)}$. This has been attributed to a 'car culture' which 'embraces and aspires to car ownership'; cars offer greater freedom than public transport with the added bonus of being a status symbol. High car usage and the lack of efficient public transport options have fostered the perception that there is no choice in transport, a mindset which is exacerbated by social status, peer pressure and culture $^{(67)}$. Malta's high motor vehicle density has exerted pressure on national transport infrastructure leading to significant capacity problems and traffic bottlenecks outside peak hours that further incapacitate the public transport system. The Public Transport Reform launched in 2011 was intended to kick-start a shift towards public transport use. However the reform did not achieve the desired effect, culminating in the transport system's re-nationalisation in December 2013 ${ }^{(68)}$. Concurrently, levels of both walking and cycling in Malta are low ${ }^{(69)}$. This has been attributed to a range of factors including Malta's hilly topography and subtropical climate, poor road conditions coupled with a lack of cycling infrastructure, road congestion, air and noise pollution, and high levels of perceived road danger ${ }^{(66,67)}$.

\section{Taxation and subsidies}

Governmental efforts to exert control on supply and availability of unhealthy food products have been rendered mostly ineffective by trade agreements, common markets 


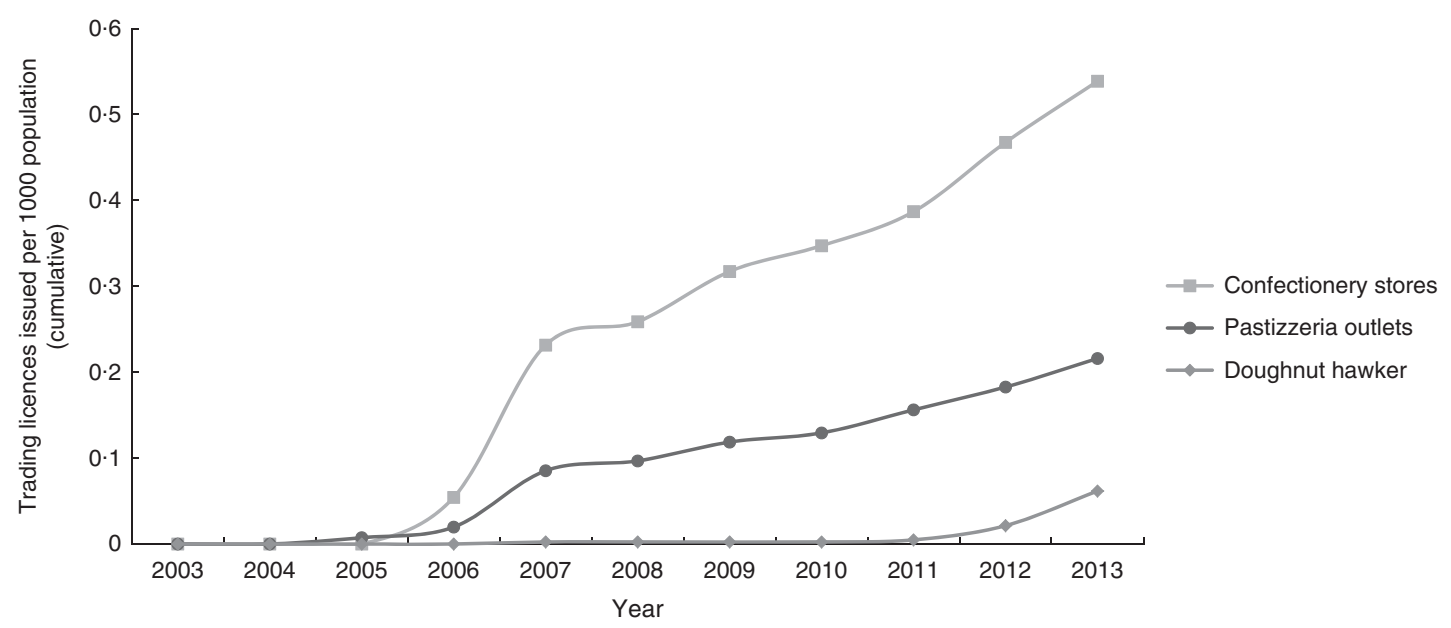

Fig. 6 New trading licences* per 1000 population issued between 2003 and 2013 for selected food outlets/mobile vendors, Malta (cumulative; from applications for food trading licenses (2003-2013) supplied by Environmental Health Directorate, Msida, Malta, personal communication, 2014). *New trading licences allowing food to be sold on-site, issued by the Environmental Health Directorate between 01/01/2003 and 31/12/2013 (showing vendors operational as of 31/01/2014)

and transnational marketing of food products and food chains $^{(16)}$. However, the feasibility of fiscal incentives to encourage healthy nutrition, increase the availability of healthy food outlets and restrict outlets selling fast foods is currently being explored by the Maltese government ${ }^{(14)}$. Malta is also a signatory to the European Charter on Counteracting Obesity ${ }^{(70)}$, which emphasised the importance of subsidies, reformulation and marketing restrictions.

\section{The micro-environment}

\section{Factors affecting nutrition}

Children tend to have limited autonomy in their food intake and physical activity levels, with the majority of their choices determined by their parents and immediate family, and to a lesser extent their peers ${ }^{(71)}$. A study on Maltese 8-10-year-olds showed that children most liked eating pasta, pizza, chips, fruit and burgers, while their least liked foods were vegetables, meat, fish, soup and fruit $^{(57)}$. They are also heavy consumers of soft drinks ${ }^{(51)}$.

\section{Community food environment}

Although self-sufficient in the production of most fresh vegetables, milk and eggs, Malta is partially dependent on imports of meat and potatoes and completely dependent on imports of grain, flour and sugar. About $71 \%$ of the island's food requirements are imported ${ }^{(55,65)}$ and this may have shaped Maltese eating habits in a process of food acculturation $^{(56)}$. Limited research on factors influencing the broader food environment in Malta exists ${ }^{(31,32)}$. There have been informal calls for action to limit proliferation of fast-food establishments or street hawkers outside schools, often frequented by children and parents immediately after school hours ${ }^{(72)}$. Small grocery stores offering fresh fruit and vegetable produce in some villages have gradually disappeared, as customers were attracted by competitive prices and wider choices offered by larger outlets. However, roving vendors selling fruit and vegetables are popular in many villages, possibly enhancing access to fresh foods for certain households $^{(16)}$. A more recent phenomenon is the presence of mobile vendors selling doughnuts, ice cream and sweets - often directly targeting children by parking in the vicinity of schools - announcing their presence with loud jingles or catchy phrases, which have proved to be extremely popular ${ }^{(72)}$. Mobile vendors have been shown to impact children's snacking opportunities ${ }^{(53)}$. In many villages, such food outlets provide a convenient alternative to cooking fresh meals. Figure 6 shows a rapid increase in the overall number of trading licences issued to confectionery stores, 'pastizzeria' outlets (stores selling cheap pastry products high in fat and sugar content and baked on-site, such as cheesecakes or sausage rolls) and - more recently - to mobile vendors selling doughnuts.

The introduction and proliferation of major fast-food chain outlets in Malta since 1995 has been followed by heavy marketing in the Maltese mass media ${ }^{(57,60)}$. It is not unusual for children to be taken to such outlets as a treat for good behaviour ${ }^{(51)}$.

\section{Educational settings}

The 2007 Healthy Eating and Lifestyle Plan (HELP) document outlines steps to be taken in schools to promote healthy lifestyles for Maltese students, providing voluntary guidelines to a health-promoting school environment and curriculum. It recommends regulation of foods sold in state school canteens and/or vending machines, as well as school policies to control content of students' packed lunches (school meals are not provided to schoolchildren in Malta) ${ }^{(20)}$. It is currently being revised prior to its introduction as standard policy in state schools. However, HELP cannot exert control over the retail environment 
outside schools, where children often purchase snacks ${ }^{(57)}$. Other efforts to improve schoolchildren's nutrition within the school setting include the provision of free milk daily to state primary-school students; the introduction of a 'Breakfast Club' offering a free healthy breakfast to children of working parents who attend state schools; and a EU co-funded 'School Fruit and Vegetable Scheme' where a portion of pre-packed fresh fruit or vegetable is given weekly to all primary-school children in Malta ${ }^{(73)}$. The 1999 Maltese National Minimum Curriculum stipulated lessons on nutrition and specifies a number of hours of Physical Education weekly, yet these are often sacrificed in favour of other academic subjects deemed to be of greater priority ${ }^{(74)}$. Currently, Physical Education policies are not consistently enforced across schools and these activities are timetabled for a range from $60 \mathrm{~min} /$ week in certain church schools to more than $120 \mathrm{~min} /$ week in independent schools ${ }^{(75)}$. Starting in September 2014, a compulsory subject (Physical Health Education) comprising elements of Physical Education and Home Economics was introduced to all primary- and secondary-school students, based on the rationale that compulsory certification might improve participation rates and decrease physical inactivity in schools ${ }^{(19)}$.

\section{Social and educational status}

Parental social and educational statuses are strongly associated with obesity ${ }^{(76-79)}$. The $2005 / 2006$ WHO HBSC survey ${ }^{(12)}$ demonstrated an inverse association between family affluence and self-reported overweight and obesity among European children. An inverse relationship between educational level and obesity in Malta was shown in the 2008 Health Interview Survey and other studies ${ }^{(5,80)}$. Economic considerations may impact familial food choices particularly during times of financial hardship: one consequence of economic insecurity as a result of the recent financial crisis is the relatively high proportion of Maltese having part-time as well as full-time jobs ${ }^{(81)}$. This may leave less time for parents to cook healthy food or accompany children outdoors, potentially leading to unhealthy food choices and lack of exercise opportunities ${ }^{(82)}$.

\section{Home food environment}

Eating behaviours and physical activity of Maltese adolescents are particularly variable and tend to be influenced by both individual and environmental factors ${ }^{(83,84)}$, as well as familial patterns of overweight ${ }^{(85)}$. Parental overweight status is itself a strong predictive risk factor for childhood obesity particularly in deprived families, whereas parental leanness seems to confer protection against development of childhood overweight regardless of family socioeconomic status ${ }^{(2,86)}$. This has significant implications for Maltese children given the large proportion of overweight and obese adults in the population. Little is known about consumption in the home; however, it has been suggested that snacks are eaten in addition to, rather than displacing, set meals in Malta, resulting in a high frequency and level of food consumption ${ }^{(51)}$.

\section{Factors affecting physical activity}

We found little information on policies or interventions that might influence physical activity levels of Maltese children in the community and at home; the majority of studies and policies identified in the literature review focused on the food environment.

\section{Physical activity in the community and at home}

Gross Domestic Product and public sector expenditure on health have been positively associated with increased leisure-time physical activity ${ }^{(87)}$. Government investment in recreational and sport facilities in Malta has gained momentum with a number of sports facilities inaugurated over the past two decades. Local sporting events are often subsidised by the government and access to fitness facilities in state-run leisure centres is heavily subsidised in a bid to encourage attendance ${ }^{(17)}$. Additionally, outdoor fitness centres are being created to provide space for physical activity (C Gauci, personal communication, 5 June 2014). Although studies on the extent of sedentariness in Maltese children are lacking, the highly prevalent use of TV and gaming technology as 'babysitting' devices has been identified as a target for action in the Healthy Weight for Life Strategy ${ }^{(14)}$.

\section{Discussion}

The health and economic costs of excess weight in Malta continue to rise, leading to a situation where the morbidity and mortality burden of obesity-related disease such as diabetes and CVD are higher than the European average $^{(7,16,54)}$. This may have been driven by a strongly obesogenic environment, with multiple drivers across different settings, sectors and the life course of unhealthy eating and low levels of physical activity. However, data characterising the links between these various environmental components and childhood obesity are currently lacking or difficult to access. There is a clear need for an integrated whole-system approach that considers both health and non-health sectors (including trade, agriculture, transport and urban planning) in order to create synergies that support sustainability of actions and policies ${ }^{(88)}$. The role of public health action should be to restore a level playing field in which physical, socio-cultural, economic and policy drivers are shifted to create healthy defaults, making healthier choices the easiest choices ${ }^{(89)}$. For example, the burgeoning agro-tourism sector in the Maltese islands might be encouraged to capitalise on its 'healthy lifestyle' message by offering cycling tours, which in turn would benefit from construction of cycle lanes between areas of interest. Encouraging active travel through provision of appropriate infrastructure would also benefit 
local mobility, thus creating a self-sustaining system that promotes an active lifestyle for all. Such multi-component, community-based initiatives have been reasonably successful in preventing obesity in children ${ }^{(48,90,91)}$ and provide bestpractice evidence for interventions that can be applied to Malta. Crucially, they are aimed both at changing children's behaviour directly and at altering their environment. We have applied the ANGELO framework to structure discussion of obesogenic factors in the Maltese environment emerging from our review.

\section{Economic factors}

Figures 1 to 4 indicate that food availability in Malta is increasing slowly but steadily even as proportional domestic expenditure on food decreases; however, this may simply reflect improving income levels in the general population $^{(24)}$. As yet, no nationally representative food consumption data are available for Malta, making it difficult to derive conclusions about proportional expenditure or nutritional habits at population level. A qualitative food consumption survey conducted in 2010 does not provide information on actual quantities of food consumed. Food balance sheet data are based on food import, export and production data, and hence should be interpreted with caution in view of potential seasonal increases in food supply in response to tourist demand. Establishing a national survey mechanism to collect trend data on food consumption (including children) and food pricing would enhance our knowledge of food habits and the influence of prices on food consumption, enabling the development of evidence-based nutrition policy recommendations targeting specific sections of the population. Other economic considerations operate at the micro level. For example, Maltese schoolchildren are often given money to purchase their own snacks on school days ${ }^{(57)}$, leading to potentially unhealthy snack purchases dependent on cost, availability and taste. Family lifestyle and socio-economic status are also likely to influence accessibility, variety and quality of food eaten by children, as well as their access to sports and recreational facilities (e.g. through parental willingness to pay for sports equipment or club membership fees).

\section{Physical factors}

While schools remain a key setting for provision of structured physical activity to Maltese children, actual time spent being physically active during a physical education lesson is limited to a small fraction of the total time allocated ${ }^{(74)}$. Regular auditing of actual time spent being physically active should be carried out in all schools on a regular basis and ideally more sessions allocated for physical activity ${ }^{(92)}$. The introduction of a new compulsory subject combining healthy eating, physical activity and body image in secondary-school curricula may help foster healthy dietary habits and enhance overall levels of physical activity, and is a recommended component of best-practice interventions ${ }^{(92)}$. This will complement an existing scheme that aims to shape children's food preferences and promote sustainable consumption of fruit and vegetables through once-weekly distribution of free fruit and vegetables portions in primary schools ${ }^{(73)}$.

At a population level, it remains to be seen whether the desired shift away from car usage towards public transport can be achieved. Furthermore, we did not find evidence of policies aiming to encourage alternative forms of urban mobility (such as through the provision of bicycle lanes) or to increase levels of physical activity in the community or at home. Further studies exploring the feasibility and effectiveness of interventions in these areas would be useful.

\section{Socio-cultural factors}

Eating habits and food preferences are established at a young age and maintained into adolescence ${ }^{(93,94)}$. Food norms are passed on across generations through a process of socialisation, moulding children's preferences ${ }^{(56)}$. In turn, preferences may influence intake either directly through children's requests to adult food providers or indirectly through adults' fulfilment of perceived children's preferences. Best-practice recommendations to create an environment and culture that support children eating nutritious foods and being active from an early age include the provision of support to school staff for the implementation of health-promotion strategies and activities and the engagement of parents to offer complementary action within the home (e.g. discourage screen-based activities) ${ }^{(95)}$.

Systematic advertising of sugar-sweetened beverages may help explain Maltese children's preference for soft drinks over water ${ }^{(51)}$ and the high rate of soft drink consumption in Malta (second only to Mexico ${ }^{(96)}$ ); however, there is a lack of evidence to support such conjectures. An analysis of online media advertising targeted at children has not yet been carried out in Malta. Additionally, a comprehensive content analysis of TV and other audiovisual media advertising that expands upon the single dissertation study tackling the topic ${ }^{(60)}$ would help formulate targeted policy responses to inappropriate advertising to children. Both multifaceted school-based programmes with active physical education components as described above, and initiatives to reduce TV advertising of high-fat and/or high-sugar foods and drinks to children, have been found to be highly cost-effective interventions ${ }^{(97)}$. At the same time, fast-food outlets continue to proliferate, advertise and innovate in response to consumer demand ${ }^{(98)}$, further compounding the change in nutrition habits. Although 'pastizzerias' and confectionery stores have been around for decades, could their recent apparent proliferation be due to changing consumer preferences, followed by a market response to demand? For example, children with working mothers may be more likely to watch more TV and eat prepared food than children with mothers who do not work outside the home or to stop at a junk-food outlet on their way to private tuition lessons after school ${ }^{(51)}$. It is difficult to clarify the links between the evolving food environment, nutritional and physical activity habits and their impact on 
obesity rates when baseline quantitative data are lacking. Although the evidence base on associations between neighbourhood environment and weight status is mixed ${ }^{(46,99)}$, local research on the potential impact of neighbourhood built and food environments on lifestyle might open up alternative avenues for policy makers in Malta to explore. Furthermore, Malta is visited by more than a million tourists annually ${ }^{(61)}$ adding yet another layer to this complex issue. It may be the case that tourism has facilitated the assimilation of non-native foods, either by mere exposure to discourse around nonMaltese cuisines or by actual provision of such cuisine in local catering establishments ${ }^{(51)}$. Working with industry to encourage reformulation of food - and limit portion sizes served at catering establishments may be an integral component of an overall strategy seeking to reduce food intake at population level.

\section{Policy factors}

The policy environment at both macro and micro levels influences behaviour. Thus informal household rules regulating time spent watching $\mathrm{TV}$, playing video games or other sedentary activities, and rules around food such as eating meals together as a family or limiting snacks, may critically shape children's attitudes towards food and physical activity levels through their lives ${ }^{(100)}$. More broadly, stateimposed regulations around food labelling and advertising aimed at children may directly or indirectly impact children's risk of overweight and obesity ${ }^{(22)}$. Currently no national standards on labelling of food items to facilitate healthy food choice exist, although the National Obesity Strategy suggests a need for such standards and EU legislation entered into application in December $2014^{(101)}$. Additionally, there has been little in the way of policy response to reduce the impact of advertising on children ${ }^{(14)}$.

\section{Conclusion}

Many aspects of the physical, social, economic and cultural environments in Malta favour a positive energy balance, characterised by limited infrastructure for active living combined with an energy-dense food supply. Alleviating the future health and economic burden of obesity-related disease will require a deeper understanding of the ways in which Malta's geopolitical background, cultural identity, physical environment and other drivers of obesity have changed over time. The collection of trend data related to food consumption, physical activity and changes to the built environment will enable the strength of interactions between these drivers to be quantified and appropriate countermeasures to be developed.

\section{Acknowledgements}

Acknowledgements: The authors would like to thank Ms Ketevan Glonti and Dr Julian Mamo for their advice during the writing of this article. Financial support: This work was supported by the Malta Government Scholarship Scheme. The Malta Government Scholarship Scheme had no role in the design, analysis or writing of this article. Conflict of interest: None. Authorship: D.C. contributed to formulating the research question, designing the study, conducting the literature search, analysing the data and writing the article. C.K. and H.R. contributed to formulating the research question and reviewing the article. Ethics of buman subject participation: Not applicable.

\section{References}

1. Dehghan M, Akhtar-Danesh N \& Merchant AT (2005) Childhood obesity, prevalence and prevention. Nutr $J$ 4, 24 .

2. Parsons TJ, Power C, Logan S et al. (1999) Childhood predictors of adult obesity: a systematic review. Int J Obes Relat Metab Disord 23, Suppl. 8, S1-S107.

3. World Health Organization (2010) Global Status Report on Noncommunicable Diseases 2010. Geneva: WHO.

4. Finucane MM, Stevens GA, Cowan MJ et al. (2011) National, regional, and global trends in body-mass index since 1980: systematic analysis of health examination surveys and epidemiological studies with 960 countryyears and 9.1 million participants. Lancet 377, 557-567.

5. Borrelli V, Giuffre M \& Buono D (2012) Snapshot on obesity in the European Union: latest results and some statistical methodological reflections. In Special issue: Abstracts from the 5th Congress of the International Federation for the Surgery of Obesity and Metabolic Disorders European Chapter (IFSO-EC), Barcelona, 26-28 April 2012. Obes Surg 22, 1144-1205.

6. Directorate of Health Information and Research, Ministry for Health, the Elderly and Community Care (2008) European Health Interview Survey 2008 - Summary Statistics. Msida, Malta: Directorate of Health Information and Research, MHEC.

7. Gatt M (2013) National Mortality Registry. Annual Mortality Report 2011. Msida, Malta: Directorate of Health Information and Research.

8. Grech V \& Farrugia Sant'Angelo V (2011) Comparison of body mass index of a national cohort of Maltese children over a 3-year interval. Malta Med J 23, 34-39.

9. Grech V \& Farrugia Sant'Angelo V (2009) Body mass index estimation in a school-entry aged cohort in Malta. Int $J$ Pediatr Obes 4, 126-128.

10. Currie C, Zanotti C, Morgan A et al. (2012) Social Determinants of Health and Well-Being Among Young People. Health Behaviour in School-aged Children (HBSC) Study: International Report from the 2009/2010 Survey. Health Policy for Children and Adolescents no. 6. Copenhagen: WHO Regional Office for Europe.

11. Wijnhoven TM, van Raaij JM, Spinelli A et al. (2012) WHO European Childhood Obesity Surveillance Initiative 2008: weight, height and body mass index in 6-9-year-old children. Pediatr Obes 8, 79-97.

12. World Health Organization (2008) Inequalities in Young People's Health. HBSC International Report from the 2005/2006 Survey. Copenhagen: WHO Regional Office for Europe.

13. Calleja N \& Gauci D (2009) The cost of obesity. In 7th Malta Medical School Conference. Msida, Malta: Department of Health Information and Research.

14. Superintendence of Public Health, Ministry for Health, the Elderly and Community Care (2012) A Healthy Weight for 
Life: A National Strategy for Malta (2012-2020). Msida, Malta: Superintendence of Public Health, MHEC.

15. Department of Health Promotion and Disease Prevention, Ministry for Health, the Elderly and Comminity Care (2010) A Strategy for the Prevention and Control of Noncommunicable Disease in Malta. Msida, Malta: Department of Health Promotion and Disease Prevention, MHEC.

16. Health Promotion and Disease Prevention Directorate, Ministry for Health (2014) Food and Nutrition Policy and Action Plan 2014-2020. Valletta: Ministry for Health.

17. Kunsill Malti gћall-Isport (2007) Re-Shaping Sport - Towards Personal Development, Health and Success. Floriana, Malta: Ministry of Education, Youth and Employment.

18. Ministry for Tourism, the Environment and Culture (2012) National Environmental Policy. Valetta: Ministry for Tourism, the Environment and Culture.

19. Ministry of Education and Employment (2012) A National Curriculum Framework for All. Floriana, Malta: Ministry of Education and Employment.

20. Ministry of Education Youth and Employment (2007) Healthy Eating Lifestyle Plan (HELP). Floriana, Malta: Ministry of Education, Youth and Employment.

21. Swinburn B, Egger G \& Raza F (1999) Dissecting obesogenic environments: the development and application of a framework for identifying and prioritizing environmental interventions for obesity. Prev Med 29, 563-570.

22. Cecchini M, Sassi F, Lauer JA et al. (2010) Tackling of unhealthy diets, physical inactivity, and obesity: health effects and cost-effectiveness. Lancet 376, 1775-1784.

23. Sassi F, Cecchini M, Lauer JA et al. (2009) Improving Lifestyles, Tackling Obesity: The Health and Economic Impact of Prevention Strategies. OECD Health Working Paper no. 48. Paris: OECD.

24. Knai C \& McKee M (2010) Tackling childhood obesity: the importance of understanding the context. J Public Health 32, 506-511.

25. Swinburn BA, Sacks G, Hall KD et al. (2011) The global obesity pandemic: shaped by global drivers and local environments. Lancet 378, 804-814.

26. Swinburn B, Sacks G, Vandevijvere S et al. (2013) INFORMAS (International Network for Food and Obesity/ non-communicable diseases Research, Monitoring and Action Support): overview and key principles. Obes Rev 14, 1-12.

27. Neal B, Sacks G, Swinburn B et al. (2013) Monitoring the levels of important nutrients in the food supply. Obes Rev 14, 49-58.

28. Lee A, Mhurchu CN, Sacks G et al. (2013) Monitoring the price and affordability of foods and diets globally. Obes Rev 14, 82-95.

29. Sacks G, Swinburn B, Kraak V et al. (2013) A proposed approach to monitor private-sector policies and practices related to food environments, obesity and noncommunicable disease prevention. Obes Rev 14, 38-48.

30. Simmons A, Mavoa HM, Bell AC et al. (2009) Creating community action plans for obesity prevention using the ANGELO (Analysis Grid for Elements Linked to Obesity) Framework. Health Promot Int 24, 311-324.

31. Gastoni M \& Atkins PJ (1997) The Maltese food system and the Mediterranean. GeoJournal 41, 127-136.

32. Mizzi L (1995) Food and nutrition policy in Malta. Food Policy 20, 475-486.

33. Helsing E (1991) Nutrition policies in Europe: background and organisation. Food Policy 16, 371-382.

34. Bellizzi M (1992) The Maltese Food Revolution: An Analysis of the Eating Habits in Malta. Technical Report of the Malta Case Study for the International Conference on Nutrition. Valletta: Department of Health.

35. Bellizzi M (1993) Changing eating habits of the Maltese. In Malta: Food, Agriculture, Fisheries and the Environment.
Options Méditerranéennes: Série B. Etudes et Recherches no. 7 pp. 55-70 [S Busuttil, F Lerin and L Mizzi, editors]. Montpellier: Centre International de Hautes Etudes Agronomiques Méditerranéennes (CIHEAM).

36. Serra-Majem L, Ferro-Luzzi A, Bellizzi M et al. (1997) Nutrition policies in Mediterranean Europe. Nutr Rev 55, 11 Pt 2, S42-S57.

37. Great Britain War Department (1839) Statistical Report on the Sickness, Mortality and Invaliding Among the Troops in the United Kingdom, the Mediterranean and the British America. London: War Department.

38. Estruch R, Ros E, Salas-Salvado J et al. (2013) Primary prevention of cardiovascular disease with a mediterranean diet. $N$ Engl J Med 368, 1279-1290.

39. Kushi LH, Lenart EB \& Willett WC (1995) Health implications of Mediterranean diets in light of contemporary knowledge. 1. Plant foods and dairy products. Am J Clin Nutr 61, 6 Suppl., 1407S-1415S.

40. Kushi LH, Lenart EB \& Willett WC (1995) Health implications of Mediterranean diets in light of contemporary knowledge. 2. Meat, wine, fats, and oils. Am J Clin Nutr 61, 6 Suppl., 1416S-1427S.

41. Kastorini CM \& Panagiotakos DB (2010) The role of the Mediterranean diet on the development of the metabolic syndrome. Front Biosci (Elite Ed) 2, 1320-1333.

42. Bautista MC \& Engler MM (2005) The Mediterranean diet: is it cardioprotective? Prog Cardiovasc Nurs 20, 70-76.

43. Babio N, Bullo M \& Salas-Salvado J (2009) Mediterranean diet and metabolic syndrome: the evidence. Public Health Nutr 12, 1607-1617.

44. Esposito K, Ciotola M \& Giugliano D (2007) Mediterranean diet and the metabolic syndrome. Mol Nutr Food Res $\mathbf{5 1}$, 1268-1274.

45. Schmidhuber J (2007) The EU diet - evolution, evaluation and impacts of the CAP. Paper presented at WHO Forum on 'Trade and bealthy food and diets', Montreal, 7-13 November 2007.

46. Tourlouki E, Matalas AL, Bountziouka V et al. (2013) Are current dietary habits in Mediterranean islands a reflection of the past? Results from the MEDIS study. Ecol Food Nutr 52, 371-386.

47. Piscopo S (2005) Global versus local: a socio-ecological study of the westernization of Maltese children's diets. Paper presented at 2nd International Institute of Consumer Sciences incorporating Home Economics, Research Conference: Consumption, Culture and Community, Liverpool John Moores University, Liverpool, UK.

48. Tessier S \& Gerber M (2005) Factors determining the nutrition transition in two Mediterranean islands: Sardinia and Malta. Public Health Nutr 8, 1286-1292.

49. World Health Organization (1986) Formulation of a Nutrition Policy: Report of the First Conference on Nutrition in Malta, 25-30 August 1986. Geneva: WHO.

50. Malta Standards Authority (2010) National Food Consumption Survey. Valletta: Malta Standards Authority.

51. Piscopo S (2004) Socio-ecological factors influencing food choices and behaviours of Maltese primary schoolchildren. PhD Thesis, University of Birmingham.

52. Currie C, Roberts C, Morgan A et al. (2004) Young People's Health in Context: International Report from the HBSC 2001/02 Survey. Health Policy for Children and Adolescents no. 4. Copenhagen: WHO Regional Office for Europe.

53. Health Promotion and Disease Prevention Directorate (2012) Highlights from the Study on Health Behaviour in School Children (HBSC) 2010. Msida, Malta: Health Promotion and Disease Prevention Directorate.

54. Formosa C, Savona-Ventura C \& Mandy A (2012) Cultural contributors to the development of diabetes mellitus in Malta. Int J Diabetes Metab 20, 25-29. 
55. FAOSTAT (2014) Food Balance Sheet - Malta. http:// faostat3.fao.org/browse/FB/*/E(accessed April 2014).

56. Fieldhouse P (1995) Food and Nutrition: Customs and Culture, 2nd ed. London: Chapman \& Hall.

57. Costa G (1998) Influences on food choice of Maltese primary school children. BEd (Hons) Dissertation, University of Malta.

58. Lissner L, Lanfer A, Gwozdz W et al. (2012) Television habits in relation to overweight, diet and taste preferences in European children: the IDEFICS study. Eur J Epidemiol 27, 705-715.

59. Fenech C (2000) The food industry: targeting children. BEd (Hons) Dissertation, University of Malta.

60. Marmara C (2003) Television food advertising targeting children - a content analysis and exploratory survey. BEd (Hons) Dissertation, University of Malta.

61. National Statistics Office (2013) Malta in Figures - 2013. Valletta: NSO.

62. Malta Environment and Planning Authority (2010) The Environment Report - Indicators 2008. Valletta: MEPA.

63. Hallal PC, Andersen LB, Bull FC et al. (2012) Global physical activity levels: surveillance progress, pitfalls, and prospects. Lancet 380, 247-257.

64. Bosdriesz JR, Witvliet MI, Visscher TL et al. (2012) The influence of the macro-environment on physical activity: a multilevel analysis of 38 countries worldwide. Int J Behav Nutr Phys Act 9, 110.

65. CountryProfiler (2011) Malta: Country fact file. http:// countryprofiler.com/CP_Malta_Report_2011 (accessed May 2014).

66. PricewaterhouseCoopers (2010) National Household Travel Survey. Marsa, Malta: Transport Malta and the Ministry for Infrastructure, Transport and Communications.

67. Malta Environment and Planning Authority (2003) Transport Topic Paper. http://www.mepa.org.mt/file.aspx?f= 3009 (accessed May 2014).

68. Sansone K (2013) New Year in, Arriva out. Times of Malta, 23 December. http://www.timesofmalta.com/articles/view/ 20131223/local/New-Year-in-Arriva-out.500112 (accessed January 2014).

69. European Commission, Directorate-General for Mobility and Transport \& Directorate-General for Communication (2013) Special Eurobarometer 406 - Attitudes of Europeans Towards Urban Mobility. Eurobarometer Wave EB794 - TNS Opinion \& Social. Brussels: European Commission.

70. World Health Organization (2006) European Charter on counteracting obesity. In WHO European Ministerial Conference on Counteracting Obesity: Diet and Physical Activity for Health, Istanbul, Turkey, 15-17 November 2006. Copenhagen: WHO Regional Office for Europe.

71. Scaglioni S, Arrizza C, Vecchi F et al. (2011) Determinants of children's eating behavior. Am J Clin Nutr 94, 6 Suppl., 2006S-2011S

72. National Audit Office (2011) Performance Audit Achieving a Healthier Nutrition Environment in Schools. Floriana, Malta: NAO.

73. Ministry for Resources and Rural Affairs (2012) Malta's National Strategy: School Fruit \& Vegetable Scheme 201114. Floriana, Malta: Ministry for Resources and Rural Affairs.

74. National Audit Office (2010) Performance Audit - Physical Education and Sport in State Primary and Secondary Schools. Floriana, Malta: NAO.

75. World Health Organization (2007) Childhood Obesity Surveillance in the WHO European Region. Copenhagen: WHO Regional Office for Europe.

76. Classen T \& Hokayem C (2005) Childhood influences on youth obesity. Econ Hum Biol 3, 165-187.

77. Faeh D, Braun J \& Bopp M (2010) Prevalence of obesity in Switzerland 1992-2007: the impact of education, income and occupational class. Obes Rev 12, 151-166.
78. Singh-Manoux A, Gourmelen J, Lajnef M et al. (2009) Prevalence of educational inequalities in obesity between 1970 and 2003 in France. Obes Rev 10, 511-518.

79. Singh GK, Siahpush M \& Kogan MD (2010) Rising social inequalities in US childhood obesity, 2003-2007. Ann Epidemiol 20, 40-52.

80. Directorate of Health Information and Research, Ministry for Health, the Elderly and Community Care (2008) European Health Interview Survey 2008 - Lifestyle Report. Msida, Malta: Directorate of Health Information and Research, MHEC.

81. National Statistics Office (2014) Gainfully Occupied Population: September 2013. Valletta: NSO.

82. Will B, Zeeb H \& Baune BT (2005) Overweight and obesity at school entry among migrant and German children: a cross-sectional study. BMC Public Health 5, 45.

83. Grundy SM (1998) Multifactorial causation of obesity: implications for prevention. Am J Clin Nutr 67, 3 Suppl., 563S-572S.

84. Selassie M \& Sinha AC (2011) The epidemiology and aetiology of obesity: a global challenge. Best Pract Res Clin Anaesthesiol 25, 1-9.

85. Birch LL \& Davison KK (2001) Family environmental factors influencing the developing behavioral controls of food intake and childhood overweight. Pediatr Clin North Am 48, 893-907.

86. Semmler C, Ashcroft J, van Jaarsveld CH et al. (2009) Development of overweight in children in relation to parental weight and socioeconomic status. Obesity (Silver Spring) 17, 814-820.

87. Van Tuyckom C (2011) Macro-environmental factors associated with leisure-time physical activity: a cross-national analysis of EU countries. Scand I Public Health 39, 419-426.

88. Gortmaker SL, Swinburn BA, Levy D et al. (2011) Changing the future of obesity: science, policy, and action. Lancet $\mathbf{3 7 8}$, 838-847.

89. Radnitz C, Loeb K, DiMatteo J et al. (2013) Optimal defaults in the prevention of pediatric obesity: from platform to practice. J Food Nutr Disord 2, 1.

90. Decelis A, Fox K \& Jago R (2013) Prevalence of obesity among 10-11-year-old Maltese children using four established standards. Pediatr Obes 8, e54-e58.

91. Bemelmans WJ, Wijnhoven TM, Verschuuren $\mathrm{M}$ et al. (2014) Overview of 71 European community-based initiatives against childhood obesity starting between 2005 and 2011: general characteristics and reported effects. BMC Public Health 14, 758.

92. Waters E, de Silva-Sanigorski A, Hall BJ et al. (2011) Interventions for preventing obesity in children. Cochrane Database Syst Rev issue 12, CD001871.

93. Birch LL \& Fisher JO (1998) Development of eating behaviors among children and adolescents. Pediatrics 101, 539-549.

94. Wang Y, Bentley ME, Zhai F et al. (2002) Tracking of dietary intake patterns of Chinese from childhood to adolescence over a six-year follow-up period. J Nutr 132, 430-438.

95. Tessier S \& Gerber M (2005) Comparison between Sardinia and Malta: the Mediterranean diet revisited. Appetite 45, 121-126.

96. The Coca-Cola Company (2010) Annual Review. http:// assets.coca-colacompany.com/ca/71/132d94654afb9a9c4dd 107ddf631/TCCC_2010_Annual_Review_Lo.pdf （accessed May 2014).

97. Haby MM, Vos T, Carter R et al. (2006) A new approach to assessing the health benefit from obesity interventions in children and adolescents: the assessing cost-effectiveness in obesity project. Int J Obes (Lond) 30, 1463-1475.

98. Anon. (2014) McDonald's McDrive opens in Gharghur. Times of Malta 13 April. http://www.timesofmalta.com/ 
articles/view/20140413/food-drink/McDonald-s-McDriveopens-in-G-arg-ur.515105 (accessed May 2014).

99. Bennie JA, Chau JY, van der Ploeg HP et al. (2013) The prevalence and correlates of sitting in European adults - a comparison of 32 Eurobarometer-participating countries. Int J Behav Nutr Phys Act 10, 107.

100. Harrison K, Bost KK, McBride BA et al. (2011) Toward a developmental conceptualization of contributors to overweight and obesity in childhood: the Six-Cs Model. Child Dev Perspect 5, 50-58.

101. Euopean Commission, Directorate-General Health and Consumers (2011) New EU law on food information to consumers - EU Regulation 1169/2011. http://ec.europa. $\mathrm{eu} /$ food/food/labellingnutrition/foodlabelling/proposed_ legislation_en.htm (accessed July 2014). 